\title{
VARIÁVEIS LIMNOLÓGICAS E MACROINVERTEBRADOS BENTÔNICOS COMO BIOINDICADORES DE QUALIDADE DA ÁGUA
}

\author{
Renata dos Santos Cardoso ${ }^{1}$
}

Camila Pontin Novaes ${ }^{2}$

RESUMO: Embora a sociedade reconheça a importância dos recursos hídricos para a dessedentação humana e animal, para a produção agrícola, para a indústria e para a produção de energia, ainda há o aproveitamento dos benefícios da água sem a devida preocupação com a preservação de sua qualidade e quantidade. Dessa forma, os impactos ambientais causados por ações antrópicas têm levado à degradação da qualidade desse recurso, o que ressalta a importância de estudos para a compreensão do comportamento do mesmo e de sua biota aquática, com a finalidade de planejamento, manutenção ou recuperação. Sendo assim, esse trabalho visou analisar variáveis físicoquímicas e biológicas em duas seções ao longo do perfil longitudinal do córrego do Cedro, em Presidente Prudente-SP, e relacioná-las com o tipo de ocupação da superfície e a qualidade da água. Os resultados obtidos demonstraram a relação intrínseca entre o meio físico que abrange o córrego estudado (uso e ocupação da superfície da bacia hidrográfica e os processos de erosão, transporte e sedimentação) e a ecologia, que

\footnotetext{
${ }^{1}$ Mestranda do Programa de Pós-Graduação em Geografia da Faculdade de Ciências e Tecnologia da UNESP, campus de Presidente Prudente-SP. E-mail: renatacardoso16@gmail.com

${ }^{2}$ Mestranda do Programa de Pós-Graduação em Geografia da Faculdade de Ciências e Tecnologia da UNESP, campus de Presidente Prudente-SP. E-mail: camilapontin@yahoo.com.br
} 

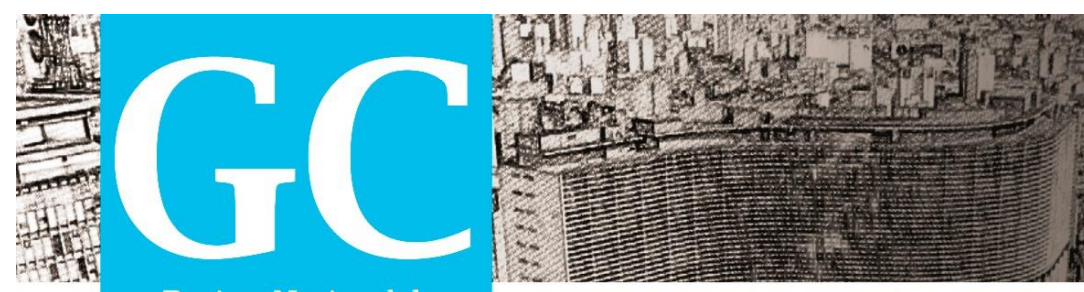

Revista Nacional de

Gerenciamento de Cidades

demonstra a adaptação das comunidades aquáticas a este meio físico alterado. Além disso, revelou a importância de um monitoramento dos recursos hídricos, visto que as modificações provocadas pela ação antrópica nos ambientes fluviais têm alterado sobremaneira sua dinâmica, poluindo as águas e interferindo negativamente na qualidade de vida no ecossistema lótico e da população.

Palavras-chave: Variáveis limnológicas. Bioindicadores. Qualidade da água.

\section{INTRODUÇÃO}

O estudo de um corpo hídrico e de sua dinâmica fluvial é utilizado na compreensão do comportamento do mesmo e de sua biota aquática, com a finalidade de planejamento, manutenção ou recuperação. Embora a sociedade reconheça a importância dos recursos hídricos para a dessedentação humana e animal, para a produção agrícola, para a indústria e para a produção de energia, ainda há o aproveitamento dos benefícios das águas fluviais sem a preocupação devida com a preservação de sua qualidade e quantidade.

Tendo em vista que o córrego do Cedro, juntamente com o córrego Botafogo, Cedrinho e o rio Santo Anastácio, são responsáveis por 30\% do abastecimento de água da Presidente Prudente, fica evidente a importância do monitoramento desses cursos d'água. Ainda mais pela área da bacia hidrográfica ser caracterizada pela ocupação desordenada da superfície, que ocasiona a impermeabilização do solo, a falta de controle dos processos erosivos, o desmatamento, o assoreamento dos corpos hídricos e sua contaminação.

Dessa forma, os impactos ambientais, causados por ações antrópicas, têm levado a uma degradação da qualidade da água em diversos corpos hídricos, dificultando a utilização de tal recurso para a satisfação até mesmo das necessidades básicas 

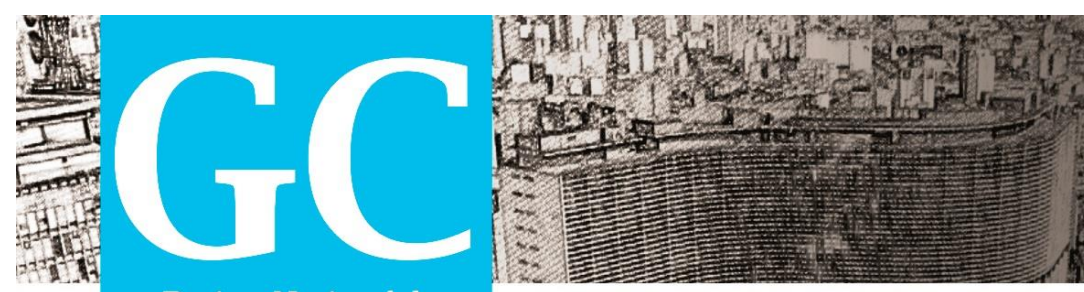

Revista Nacional de

Gerenciamento de Cidades

humanas. Portanto, Cangani et al (2008) destaca que o primeiro passo para a resolução dos problemas sócio-ambientais gerados pela má gestão dos recursos hídricos é o desenvolvimento/aplicação de metodologias de diagnóstico eficientes.

Sabe-se que o ambiente fluvial apresenta mudanças em suas características da nascente à foz, tanto no que diz respeito à morfologia do sistema, quanto às variáveis ecológicas. Assim sendo, esse trabalho visou analisar variáveis físico-químicas (o potencial hidrogeniônico $(\mathrm{pH})$, o oxigênio dissolvido (OD), a temperatura, a turbidez e a condutividade elétrica) e biológicas (comunidade de macroinvertebrados bentônicos) em duas seções ao longo do perfil longitudinal do córrego do Cedro e relacioná-las com o tipo de ocupação da superfície e a qualidade da água.

\section{CARACTERIZAÇÃO DA ÁREA DE ESTUDO}

A bacia hidrográfica do córrego do Cedro, com área total de 40,36 km², está localizada na área sul do município de Presidente Prudente-SP, mais precisamente entre

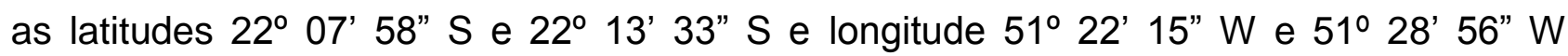
(DIBIESO, 2007).

No que diz respeito aos tipos de uso e ocupação da terra na bacia hidrográfica do córrego do Cedro (Figura 1), observam-se área urbana, solo exposto, resquícios de mata nativa e o predomínio de agropecuária. A área urbana da bacia começou a ser implantada a partir de 1953 com o bairro Vila Nova Prudente, quando a malha urbana de Presidente Prudente cresceu para além da Rodovia Raposo Tavares (DIBIESO, 2007). 

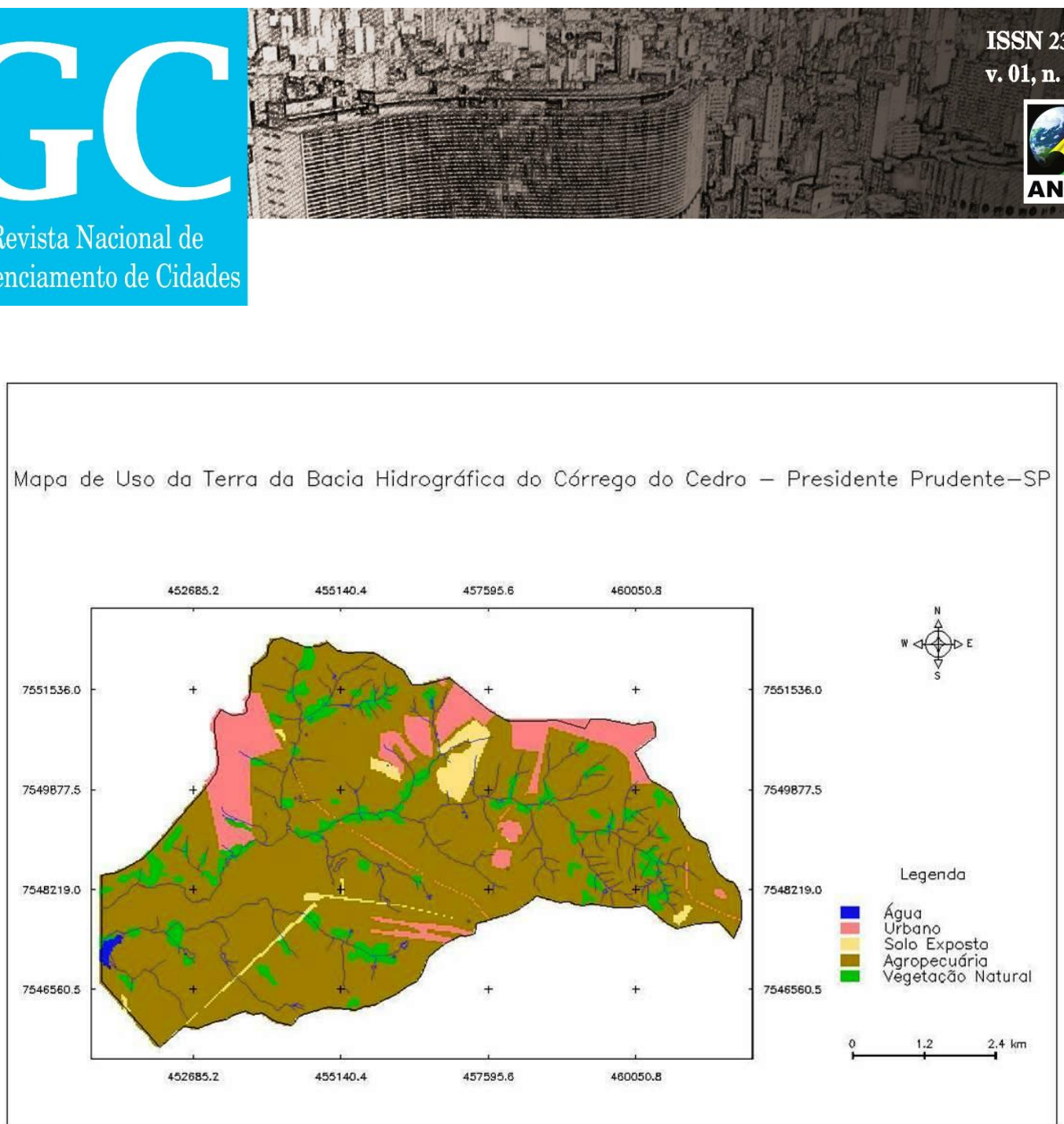

Figura 1 - Mapa de Uso e Ocupação de Terra da Bacia Hidrográfica do Córrego do Cedro, Presidente Prudente-SP. Org.: CARDOSO (2011).

Estas áreas urbanas estão localizadas, majoritariamente, na margem direita do córrego do Cedro e possuem variados padrões de tipo de uso e ocupação da superfície. Sendo que, atualmente, dentro da área da bacia encontram-se 7 bairros residenciais, 5 Residenciais de alto padrão, como o Dahma I, II e III, além de 2 conjuntos habitacionais, o Ana Jacinta e o Mario Amato.

As áreas com solo exposto apresentam-se extremamente susceptíveis a processos erosivos, e geralmente se encontram sem cobertura por serem preparadas para o plantio. No entanto, na região da bacia do córrego do Cedro, são encontrados solos expostos derivados também de loteamentos urbanos à espera de construções e de algumas áreas que já se encontram degradadas.

Sobre a vegetação nativa, Dibieso (2007) explica que esta é classificada como Floresta Tropical Semidecidual, caracterizada por apresentar queda de folhas durante a 

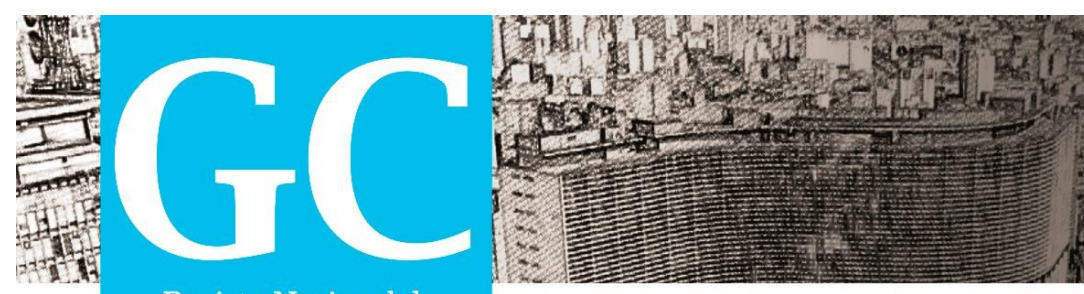

Revista Nacional de

Gerenciamento de Cidades

estação seca, árvores que atingem aproximadamente 20 metros de altura, altíssima diversidade de espécies e alta taxa de endemismo. Entretanto, essas formações florestais sofreram e ainda sofrem grande pressão antrópica, sendo que as árvores de madeira "nobre" já foram retiradas e os resquícios de mata nativa são frequentemente invadidos por gado, que pisoteiam ou pastam.

Conforme o mesmo autor, restam somente $4,78 \%$ da vegetação nativa e estas se localizam em áreas de difícil acesso, ou seja, onde se encontram as declividades mais acentuadas e próximas aos cursos d'água. Assim, nota-se que mesmo a vegetação nativa sendo escassa, esta é de extrema importância para a contenção de maiores processos erosivos, uma vez que protegem os cursos d'água e as altas declividades.

Quanto à agropecuária, as áreas de uso e ocupação rural do solo na bacia do córrego do Cedro são caracterizadas tanto por pequenas quanto por grandes propriedades, sendo que das 159 existentes 31\% possuem área de 0,5 a 2,4 ha, 18\% de 10,8 a 14,5 ha, $5 \%$ de 28,0 a 38,7 ha e apenas $2 \%$ das propriedades possuem área superior a 80 ha. Nestas propriedades, as principais atividades desenvolvidas estão voltadas à pecuária, tendo, desta forma, implicações diretas no uso e ocupação da terra, pois $74,48 \%$ da área da bacia é ocupada por pastagens e somente $2,73 \%$ por agricultura (DIBIESO, 2007).

Em relação aos cursos d'água, o principal córrego da bacia em estudo é o córrego do Cedro, que nasce ao Sul de Presidente Prudente e percorre $12 \mathrm{~km}$ de canal principal, no sentido E-SW. Este córrego, juntamente com o córrego do Cedrinho e o rio Santo Anastácio formam a represa de abastecimento público de Presidente Prudente, utilizada pela Sabesp, que se localiza no extremo oeste da bacia. Além disso, há a presença de lagoas, geralmente utilizadas para a dessedentação animal (DIBIESO, 2007).

\section{MATERIAL E PROCEDIMENTOS METODOLÓGICOS}




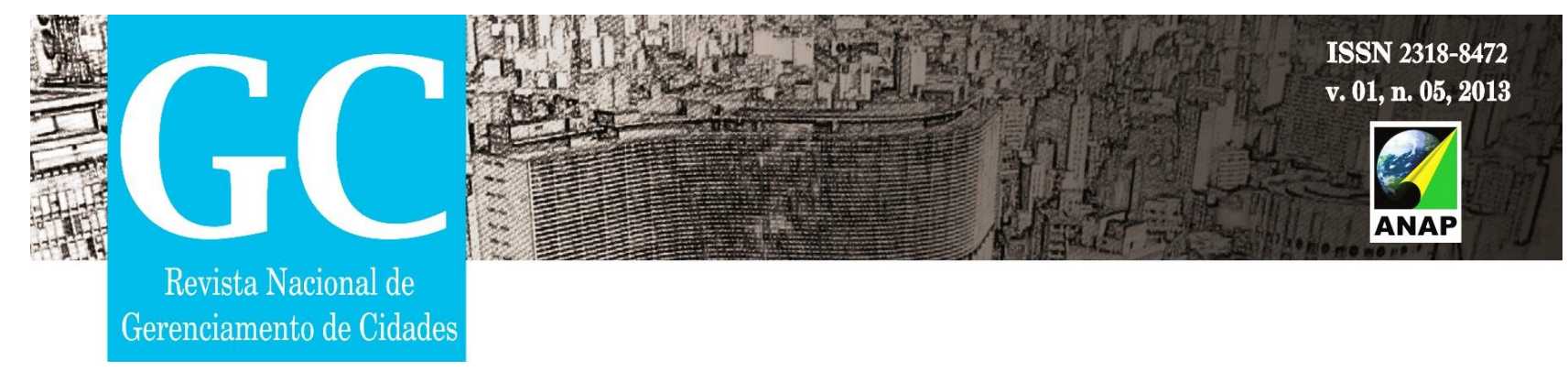

Para a realização desse trabalho, foram escolhidos dois pontos de coleta e medição de dados que apresentaram características diferenciadas de uso e ocupação da superfície, mas principalmente pela localização no perfil longitudinal do córrego do Cedro. Assim, para as amostragens realizadas no dia 13 de junho de 2013, o primeiro ponto selecionado foi próximo ao alto curso (seção 1), enquanto o segundo (seções $2 \mathrm{~A}$ e 2B) foi em direção ao baixo curso do rio (Figura 2).

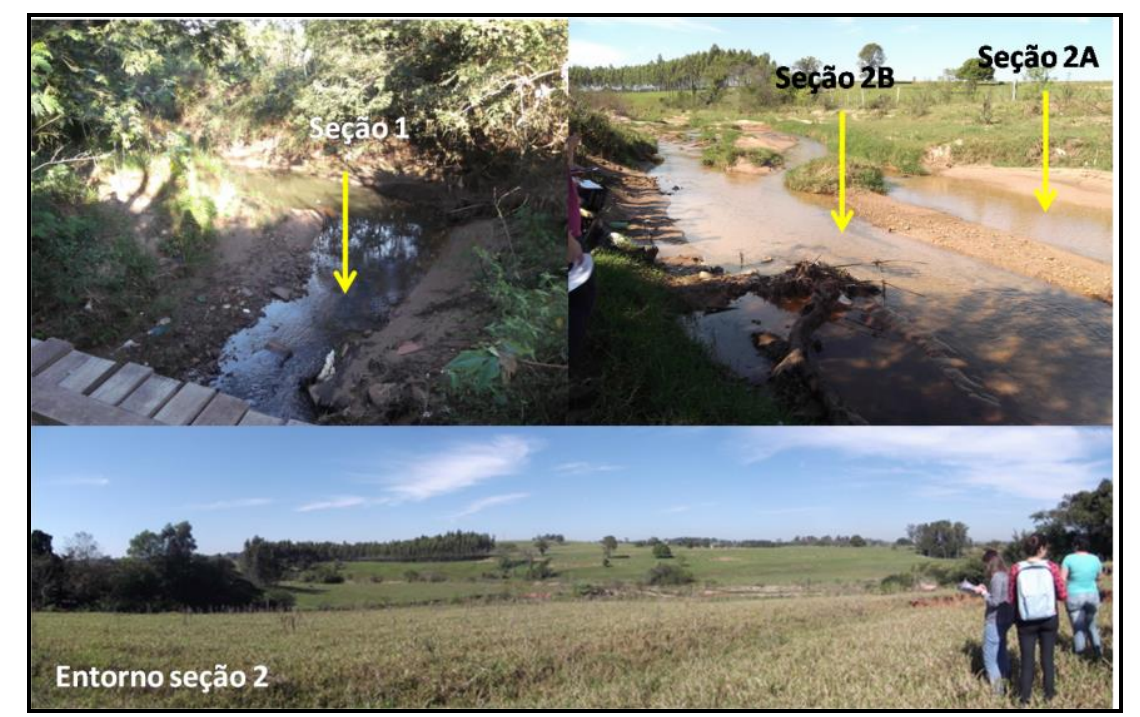

Figura 2 - Pontos de amostragem no córrego do Cedro (Seção 1 e Seções 2A e 2B). Fonte: CARDOSO; NOVAES (2013).

Primeiramente, foram mensurados in loco 5 variáveis físico-químicas em duas seções no córrego do Cedro, sendo elas: o pH, o oxigênio dissolvido, a turbidez, a condutividade elétrica e a temperatura. Para amostrar tais variáveis, utilizou-se um pHmetro analógico portátil, um oxímetro digital portátil, um turbidímetro portátil e um termômetro (Figura 3). 

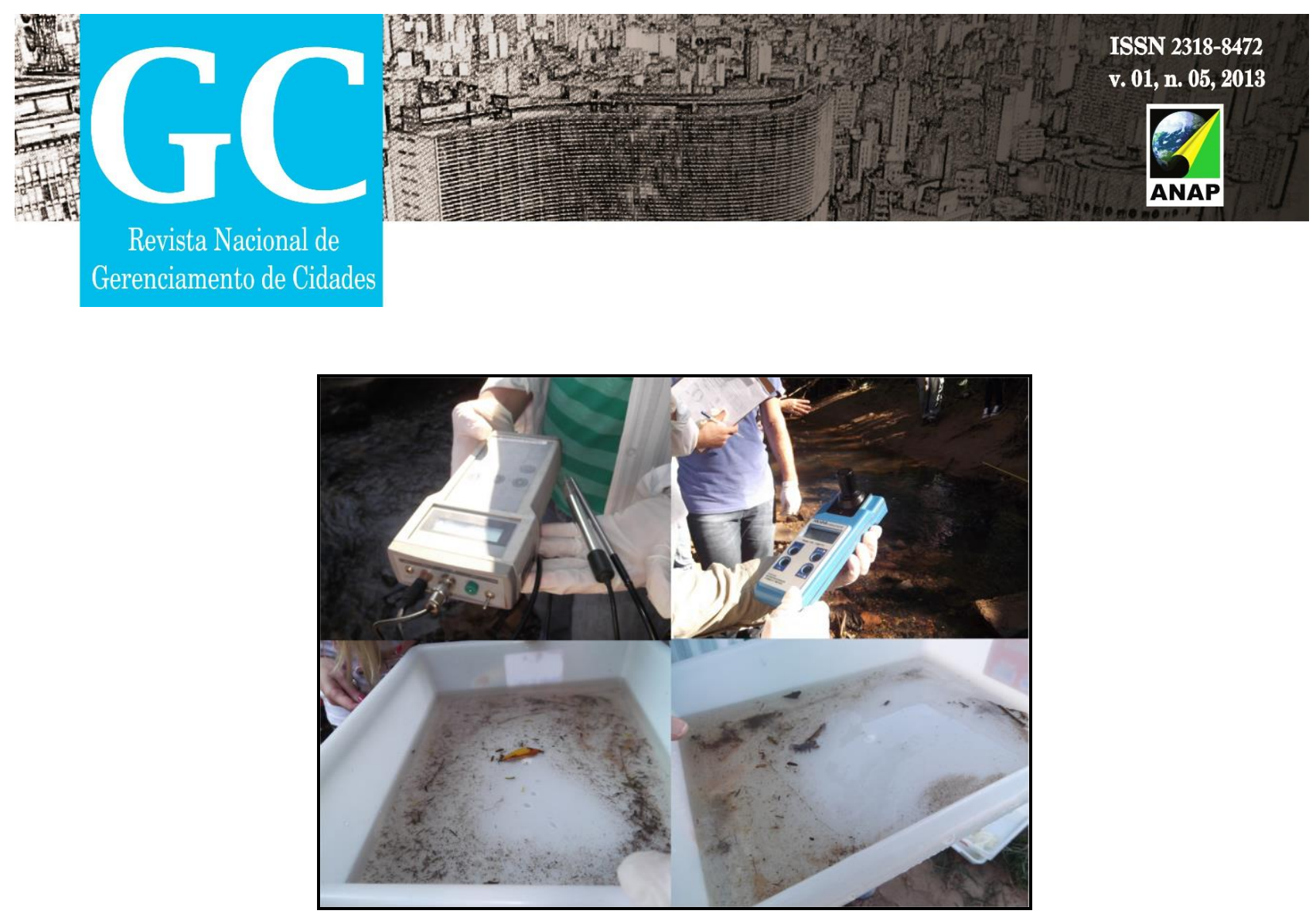

Figura 3 - Equipamentos para a medição das variáveis físico-químicas e zoobentos coletados. Fonte: CARDOSO; NOVAES (2013).

Posteriormente, foram coletados os macroinvertebrados bentônicos (zoobentos) no curso d'água a partir da agitação do leito das seções (Figura 3), pois assim ficaram em suspensão e puderam ser colhidos com maior facilidade numa peneira e levados ao laboratório para análise.

\section{RESULTADOS E DISCUSSÕES}

\subsection{Variáveis limnológicas}

A qualidade da água pode ser analisada através de variáveis limnológicas de ordem física, química ou biológica. Dentre elas podem-se citar o potencial hidrogeniônico $(\mathrm{pH})$, o oxigênio dissolvido (OD), a temperatura, a turbidez e a condutividade elétrica (Tabela 1), variáveis estas amostradas em campo e descritas abaixo.

Tabela 1 - Valores dos parâmetros analisados.
Variáveis Físico-Químicas
Seção 1
Seção 2 


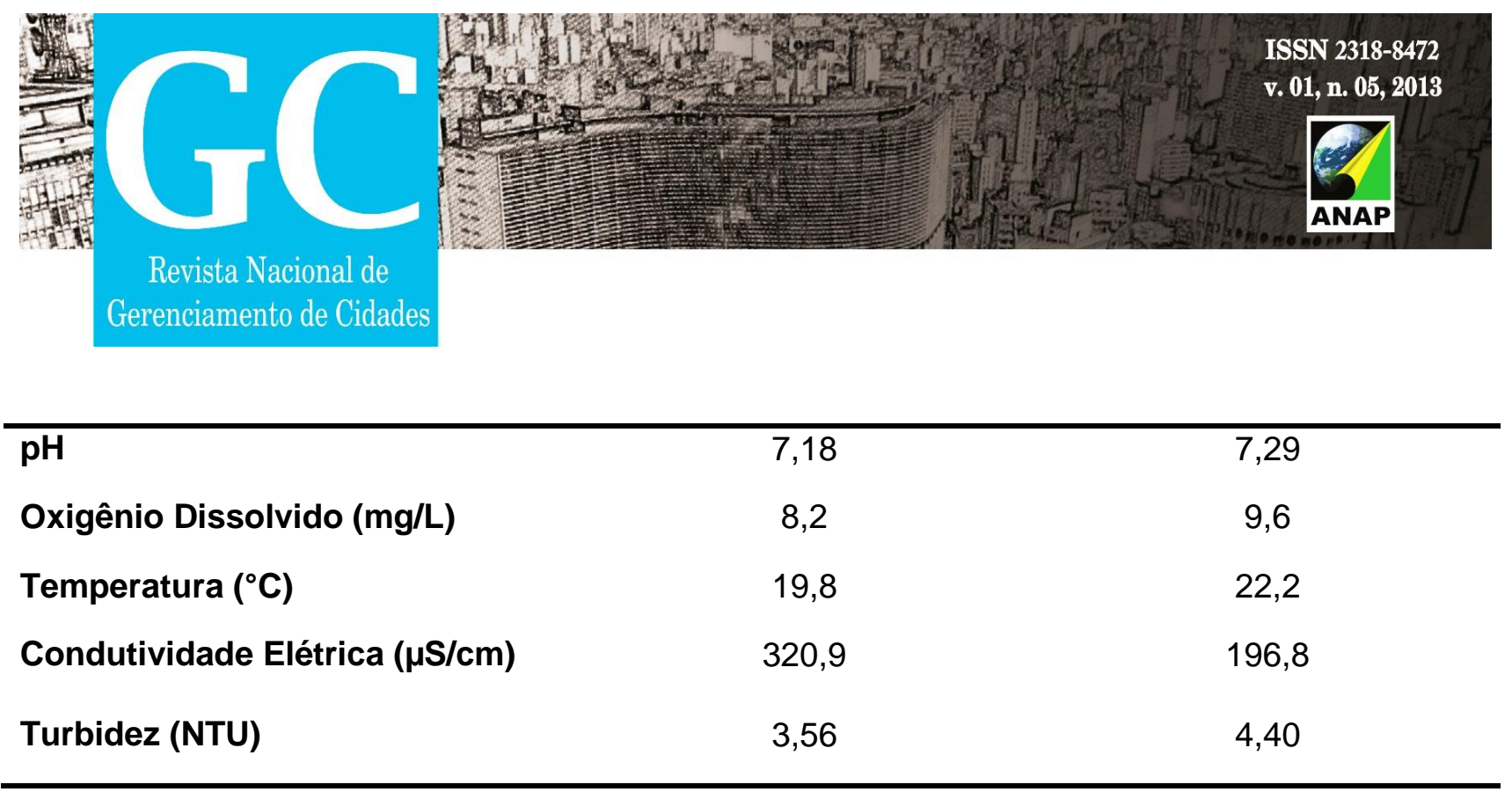

Fonte: Dados mensurados em campo (2013).

A variável $\mathrm{pH}$ é usada para expressar o grau de acidez ou alcalinidade de uma solução aquosa, isto é, expressar a concentração de íons de hidrogênio nessa solução. A escala de $\mathrm{pH}$ é constituída de uma série de números variando de 0 a 14, sendo que 70 $\mathrm{pH}$ é neutro, valores acima de 7 (até 14) indicam o aumento do grau de alcalinidade e abaixo de 7 (até 0) o aumento do grau de acidez do meio (CETESB, 2013a).

A influência do $\mathrm{pH}$ sobre os ecossistemas aquáticos naturais ocorre diretamente devido a seus efeitos sobre a fisiologia das diversas espécies, e a alteração do grau de acidez ou neutralidade das águas pode decorrer da elevada atividade fotossintética, quando o pH tende a aumentar (floração de algas, independente da alga ser tóxica ou não). Com a diminuição do pH da água (por meio do despejo de ácidos, por exemplo), os peixes apresentarão uma maior frequência respiratória, passando a abocanhar o ar na superfície. Por outro lado, em pH extremamente baixo, ocorre morte imediata. A amônia, por exemplo, quando presente no meio em $\mathrm{pH}$ acima de 9 e altas temperaturas tende a ser altamente tóxica. Já alguns metais em $\mathrm{pH}$ menor que 4 apresentam uma maior toxicidade (CETESB, 2013a).

Vale destacar que de acordo com a Resolução CONAMA nํ 357, de 17 de março de 2005, o córrego do Cedro é classificado como Classe II, cuja água pode ser destinada: a) ao abastecimento para consumo humano, após tratamento convencional; b) à proteção das comunidades aquáticas; c) à recreação de contato primário, tais como natação, esqui aquático e mergulho, conforme Resolução CONAMA nํ274, de 2000; d) à irrigação de 

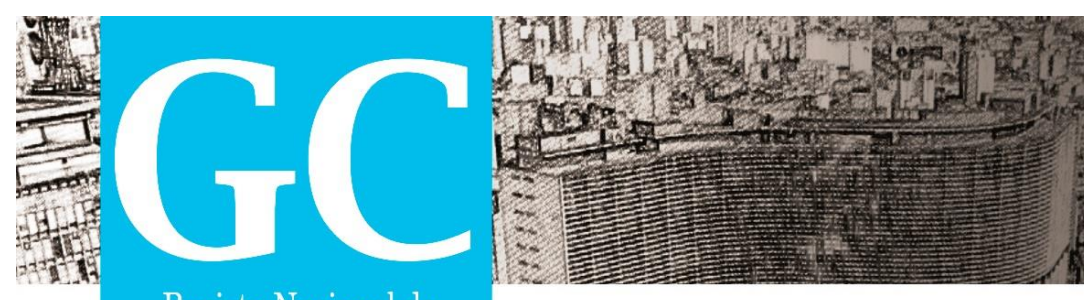

Revista Nacional de

Gerenciamento de Cidades

hortaliças, plantas frutíferas e de parques, jardins, campos de esporte e lazer, com os quais o público possa vir a ter contato direto; e e) à aquicultura e à atividade de pesca.

Para esse tipo de classe, a Resolução CONAMA 357/05 estipula que a faixa de pH deve ser de 6,0 a 9,0. E conforme os valores obtidos em campo, 7,18 na seção 1 e 7,29 na seção 2, percebe-se que o córrego do Cedro se encontra dentro da faixa de $\mathrm{pH}$ permitida.

No que diz respeito à variável oxigênio dissolvido (OD), sua introdução na água pode se dar através do ar atmosférico, do processo de fotossíntese e da ação de aeradores ou insufladores de ar, e seu teor varia principalmente com a temperatura, altitude e velocidade do curso d'água. Segundo Cangani et al (2008), as reduções nas concentrações de oxigênio nos corpos d'água são provocadas principalmente por despejos de origem orgânica. Por isso, trata-se de um indicador essencial, pois permite a avaliação da eficiência do tratamento dos esgotos na etapa da oxidação bioquímica, por exemplo, além da capacidade de um corpo d'água de manter sua vida aquática.

De acordo com informações do Instituto de Tecnologia da Universidade Federal Rural do Rio de Janeiro (2013), temperaturas muito altas limitam a disponibilidade de oxigênio, o que pode levar à morte da fauna. Isso porque a temperatura exerce maior influência nas atividades biológicas e no crescimento, além de governar os tipos de organismos que podem viver ali: peixes, insetos, zooplâncton, fitoplâncton e outras espécies aquáticas.

Cada organismo aquático tem uma faixa preferida de temperatura para se desenvolverem. Se essa faixa for ultrapassada (para menos ou para mais), o número de indivíduos das espécies diminui até se extinguirem totalmente. A temperatura ainda influi na química da água, haja vista que alguns compostos são mais tóxicos para a vida aquática nas temperaturas mais elevadas (UFRRJ, 2013).

A temperatura também comanda uma importante característica física da água: a densidade. A água difere da maioria dos compostos porque ela é menos densa no estado sólido do que no seu estado líquido (o normal). Portanto, quando as diferenças de 

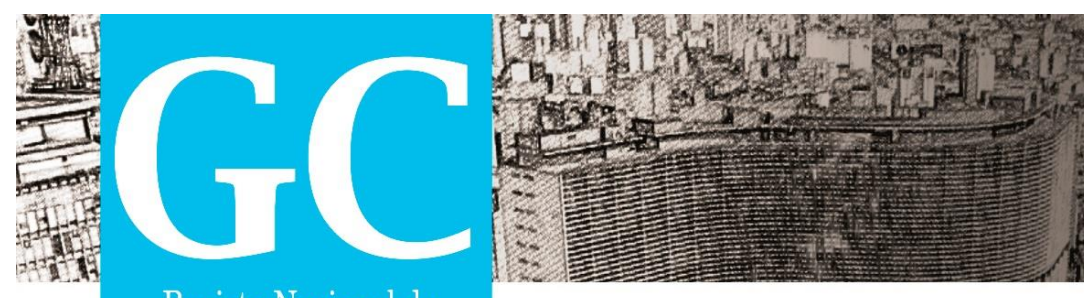

Revista Nacional de

Gerenciamento de Cidades

temperatura geram camadas d'água com diferentes densidades, formam-se barreiras físicas que impedem que se misturem.

Caso a energia do vento não seja suficiente para misturá-las, o calor não se distribui uniformemente na coluna d'água, criando assim uma condição de estabilidade térmica, na qual o ecossistema aquático fica estratificado termicamente, com diferentes características físicas, químicas e biológicas (UFRRJ, 2013).

Como a temperatura da água é ditada pela radiação solar, salvo em situações de despejos industriais, percebeu-se que a diferença de $2,4^{\circ} \mathrm{C}$ entre as seções 1 e 2 podem estar relacionadas, principalmente, pelo fator do sombreamento. Na região das cabeceiras, onde há mais vegetação arbórea nas vertentes e o canal é mais estreito, ocorre pouca incidência de raios solares, enquanto em direção ao baixo curso verificou-se o aumento da largura do canal e predomínio de pastagens, o que possibilita maior insolação e aquecimento da água.

Conforme destaca Cangani et al (2008, p. 2), a turbidez consiste o grau de "atenuação de intensidade que um feixe de luz sofre ao atravessar um corpo d'água, devido à presença de materiais em suspensão na água, finamente divididos ou em estado coloidal, e de organismos microscópicos". A erosão das margens dos rios em estações chuvosas e o transporte de sedimentos das vertentes até os cursos d'água por escoamento superficial, por exemplo, intensificados pelo mau uso do solo, são fenômenos que resultam no aumento da turbidez das águas.

Nesse sentido, os esgotos domésticos e diferentes efluentes industriais também provocam elevações na turbidez das águas, sendo que a alta turbidez provoca a redução da fotossíntese de vegetação enraizada submersa e algas. Esse desenvolvimento reduzido de plantas pode, por sua vez, acabar com a produtividade de peixes. Logo, a turbidez pode influenciar também nas comunidades biológicas aquáticas, além de afetar os usos doméstico, industrial e recreacional de uma água (CETESB, 2013b).

Quanto à variável condutividade elétrica, esta se refere à expressão numérica da capacidade de uma água conduzir a corrente elétrica. Dependendo das concentrações 

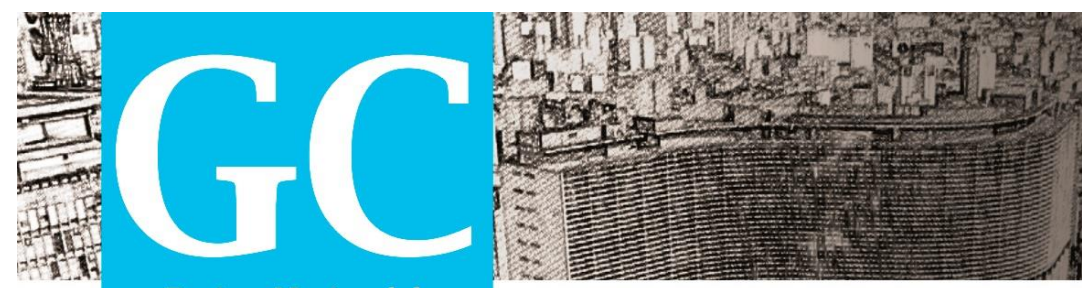

Revista Nacional de

Gerenciamento de Cidades

iônicas e da temperatura, a condutividade também indica a quantidade de sais existentes na coluna d'água e, portanto, representa uma medida indireta da concentração de poluentes (CETESB, 2013c).

Para a análise da qualidade das águas, a CETESB (2013c) ressalva que, em geral, níveis superiores a $100 \mu \mathrm{S} / \mathrm{cm}$ indicam ambientes impactados. Entretanto, através dos dados amostrados em campo, de $320 \mu \mathrm{S} / \mathrm{cm}$ na seção 1 e 196,8 $\mu \mathrm{S} / \mathrm{cm}$ na seção 2, podese dizer que o córrego do Cedro apresenta indícios de que houve emissão de esgoto doméstico ou outra fonte de contaminação. Principalmente no ponto à montante, com valor de condutividade mais elevado, visto que a condutividade da água tende a aumentar à medida que mais sólidos dissolvidos são adicionados.

Em suma, ao analisar os dados obtidos nas amostragens de cada seção, foi possível observar que, com exceção da condutividade elétrica, os valores de pH, oxigênio dissolvido e turbidez estão dentro dos limites estabelecidos pela Resolução CONAMA n`357/05 (Tabela 2) para corpos d’água Classe II.

Tabela 2 - Parâmetros das águas de Classe 2.

\begin{tabular}{cc}
\hline Parâmetro & Valor Máximo \\
\hline Turbidez & 100 (NTU) \\
OD & nunca inferior a $5 \mathrm{mg} / \mathrm{L}$ \\
pH & 6 a 9 \\
\hline
\end{tabular}

Fonte: FERRAZ; AMARAL (2010). Adaptado por: CARDOSO; NOVAES (2013).

\subsection{Conceito de continuum do rio}

O conceito de continuum do rio (CCR) considera o ecossistema fluvial como uma série integrada do gradiente físico com o ajustamento da biota associada. Assim, os rios são vistos como sistemas ligados longitudinalmente, nos quais o padrão de zonação dos agrupamentos de espécies observados é organizado de acordo com o fluxo orgânico de 

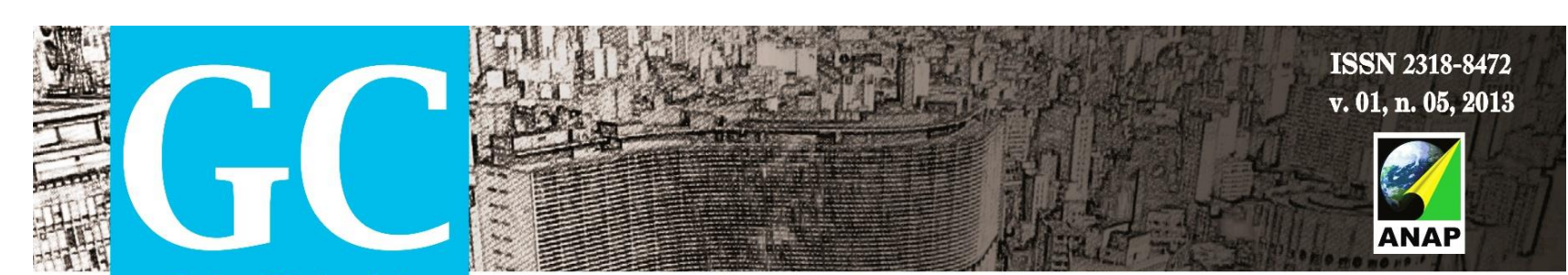

Revista Nacional de

Gerenciamento de Cidades

energia. Isto leva as comunidades posicionadas em trechos abaixo a depender dos processos acontecidos rio acima (VANNOTE et al., 1980).

Deste modo, o CCR prediz que as comunidades apresentariam padrões previsíveis de organização estrutural e funcional, conforme sua posição relativa ao longo do perfil longitudinal (BAPTISTA, D. F. et al., 1998). Sendo que os fatores de exposição à luz solar (interferência na produção de biomassa, fotossíntese) e a temperatura (interferência na reprodução, metabolismo), são importantes influências na determinação da estrutura funcional (Figura 4).

Na seção 1 do córrego do Cedro, por exemplo, o canal é estreito, profundo (em relação à seção 2 na foz) e se encontra sob condições de sombreamento devido à vegetação presente em suas margens. Diante destas características, pode-se dizer que a luz constitui um fator limitante à produção primária, o que explicaria, portanto, o valor inferior de oxigênio dissolvido neste local $(8,2 \mathrm{mg} / \mathrm{L})$. 


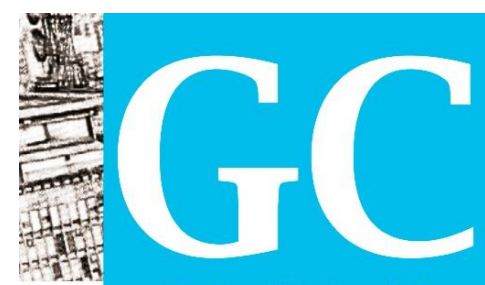

Revista Nacional de

Gerenciamento de Cidades

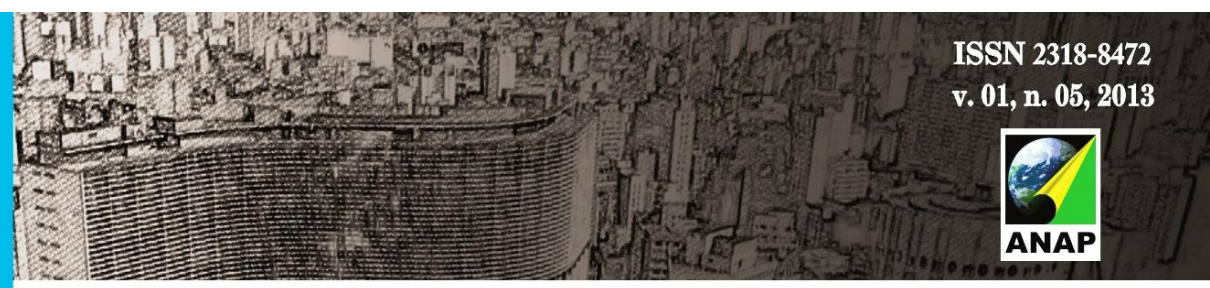

v. $01, \mathrm{n}, 05,2013$

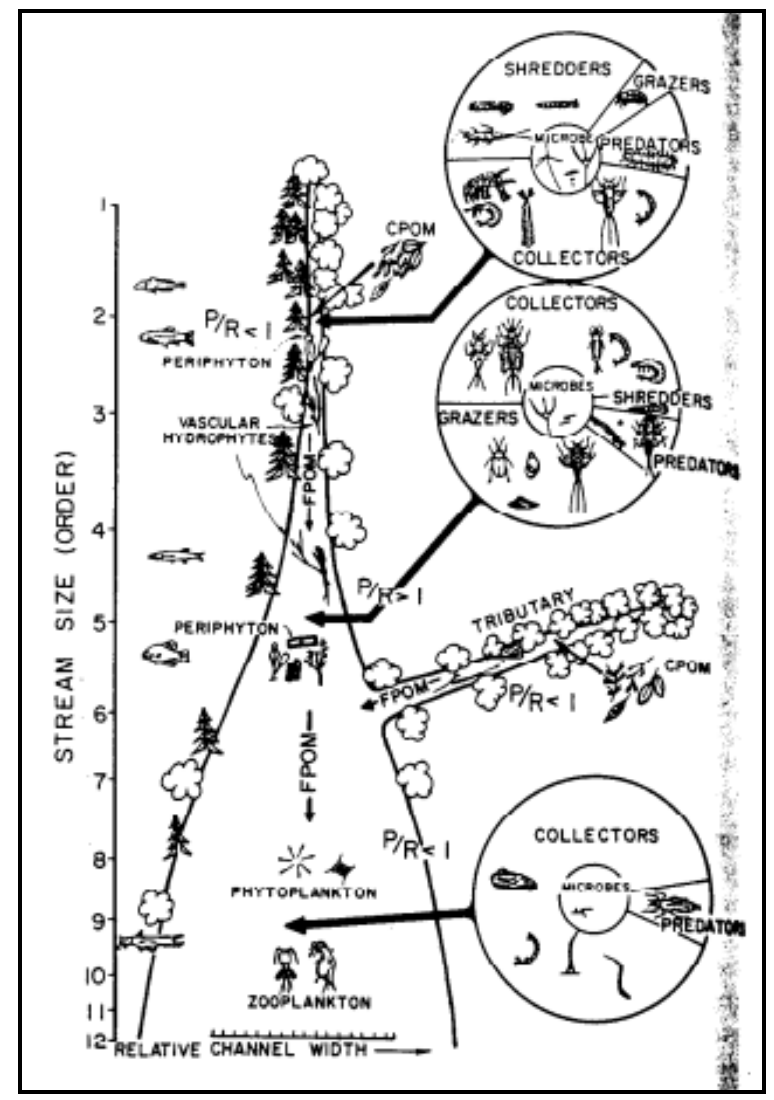

Figura 4 - Relação proposta entre o tamanho do fluxo e a progressiva mudança nos atributos estruturais e funcionais em comunidades lóticas. Fonte: VANNOTE et al (1980).

O CCR também define que os materiais predominantes nas cabeceiras são detritos alóctones (material particulado grosseiro), conferindo uma menor quantidade de material dissolvido (ARROIO JUNIOR et al, 2011). Tal fator esclareceria o menor valor de turbidez na seção 1, porém não se aplicaria à condutividade, pois o trecho à montante apresentou valor bem superior (320,9 $\mu \mathrm{S} / \mathrm{cm})$ quando comparado à seção $2(196,8 \mu \mathrm{S} / \mathrm{cm})$.

Arroio Junior et al (2011) também apresenta que com o aumento da turbidez da água ocorre uma redução da zona eufótica e, em razão disso, uma menor taxa fotossintética, o que resulta menores valores de oxigênio dissolvido. Além disso, as temperaturas elevadas diminuem a solubilidade do gás oxigênio em ambientes aquáticos, o que pode estar relacionado à ocorrência de maiores valores de OD em temperaturas 

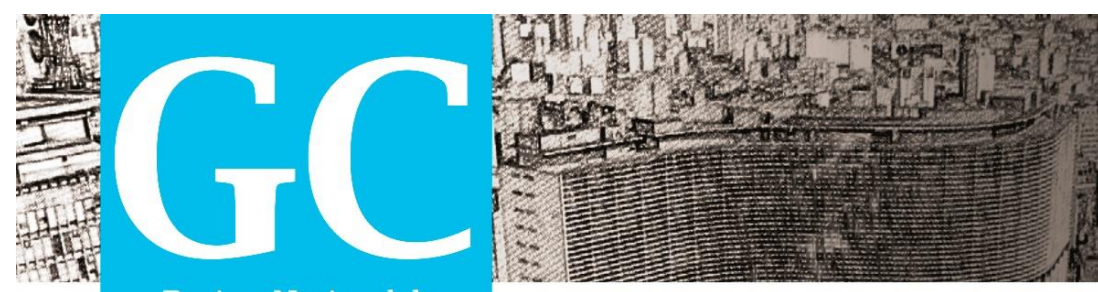

Revista Nacional de

Gerenciamento de Cidades

baixas (relação que não foi observada nas seções amostradas).

Todavia, é importante ressaltar que a teoria do contínuo fluvial foi desenvolvida para ecossistemas de rios naturais. $\mathrm{E}$ que os ambientes lóticos com interferências antrópicas, como é o caso do córrego do Cedro, podem apresentar diferenças em relação ao modelo geral. Além disso, no que se refere à autotrofia e heterotrofia do sistema, dependendo do volume e da natureza dos tributários que deságuam na corrente principal, os efeitos podem ser localizados e com magnitudes variáveis.

\subsection{Macroinvertebrados bentônicos}

A análise físico-química e biológica de um canal tem como objetivo compreender o funcionamento desse ecossistema, bem como identificar possíveis problemas que necessitam de intervenção. Nesse sentido, os estudos e a avaliação da qualidade da biota bentônica possuem inúmeras vantagens:

Os macroinvertebrados bentônicos são considerados bons indicadores de qualidade de água por possuírem ciclos de vida com duração mais longa que os planctônicos, e viverem de forma séssil durante semanas a alguns meses no compartimento sedimentar. Por este motivo, o seu monitoramento torna-se mais eficiente que o monitoramento baseado apenas na mensuração de parâmetros físicos e químicos (CALLISTO; MORENO 2006, p. 40).

Os macroinvertebrados bentônicos têm sido amplamente utilizados como bioindicadores de qualidade ambiental, visto que permitem uma avaliação integrada dos efeitos ecológicos provocados por múltiplas fontes de poluição (DODDS et al., 1998; CALLISTO et al., 2001, apud SANTOS et al., 2011), devido à sensibilidade de determinados organismos a pequenas perturbações que não precisam necessariamente ter ocorrido no local da coleta (MATOS, 2009).

Quanto à classificação dessa biota aquática, com base no modo de alimentação, os macroinvertebrados podem ser divididos em cinco categorias: 1) coletores-catadores - 

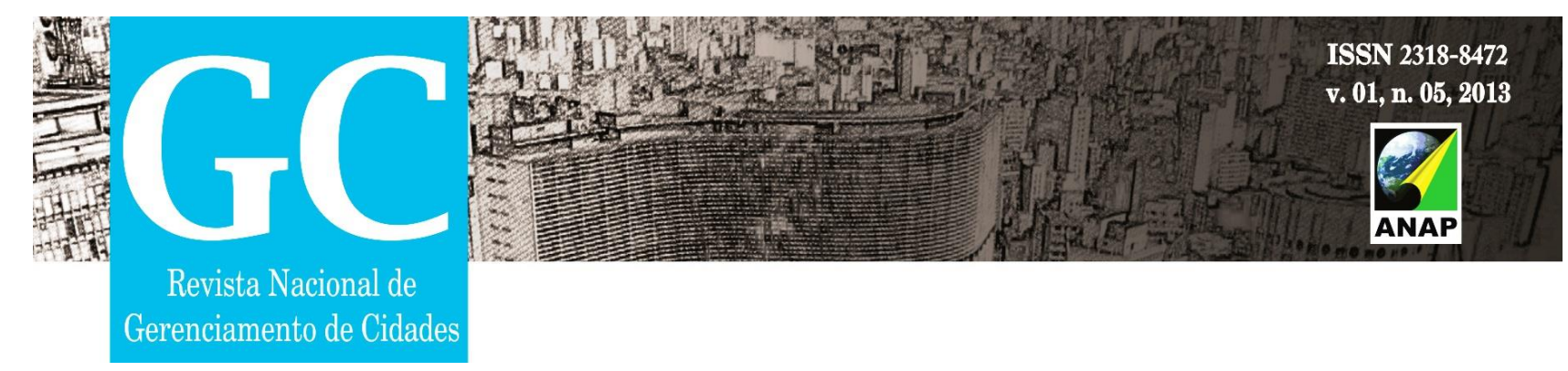

alimentam-se de pequenas partículas de matéria orgânica por coleta nos depósitos de sedimento; 2) coletores-filtradores - capturam, por filtração, pequenas partículas de matéria orgânica em suspensão na coluna d'água; 3) fragmentadores - mastigam folhas ou tecido de planta vascular vivo ou escavam madeira; 4) predadores - engolem a presa inteira ou ingerem os fluidos do tecido corporal; 5) raspadores - adaptados a raspar superfícies duras, alimentam-se de algas, bactérias, fungos e matéria orgânica morta adsorvidos aos substratos (CUMMINS; MERRITT, 1996, apud SILVA et al., 2009).

Com base no Guia de Identificação Biológica (Figuras 5 e 6), foram identificados os organismos macroinvertebrados bentônicos presentes nos pontos de coleta (seções $1 \mathrm{e}$ 2), do córrego do Cedro, bem como a representação da qualidade da água através destes, expressos nas Tabelas 3 e 4.
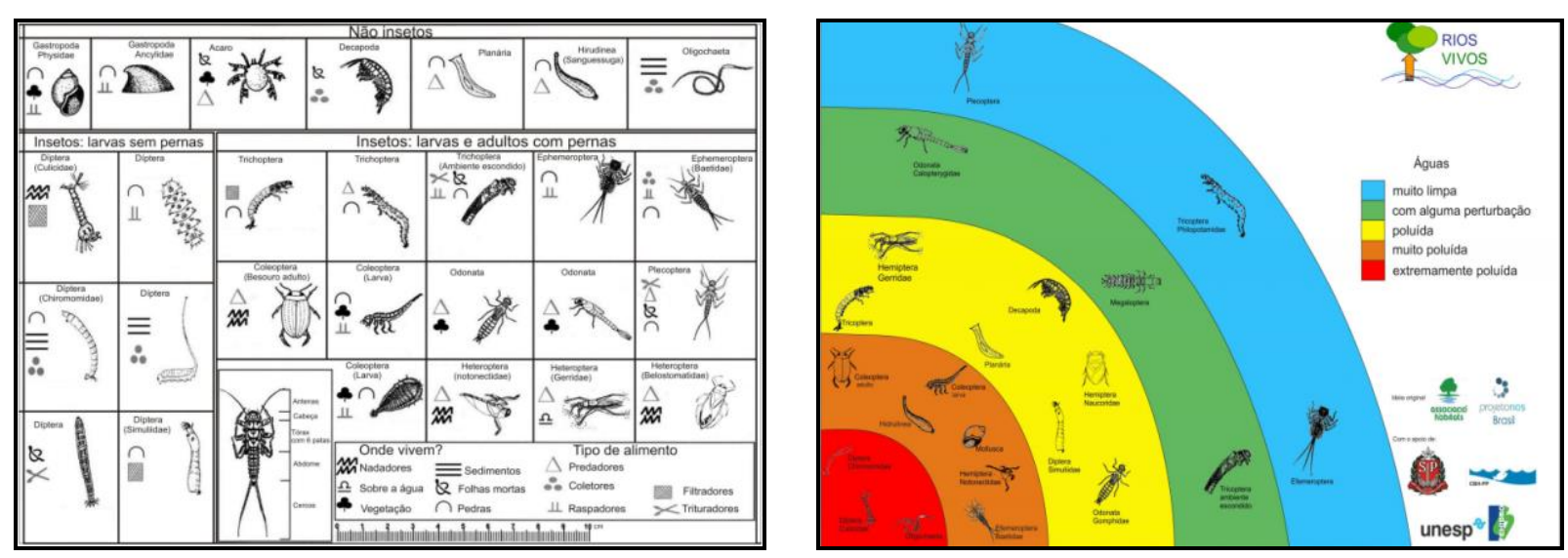

Figuras 5 e 6 - Guia de Identificação Biológica.

Fonte: <http://bacias.fct.unesp.br/riosvivos/index.php?p=visualizar

pdf\&url=documentos/materiais_didaticos/guia_identificacao_biologico.pdf.>. Acesso em: 26 jun.2013.

Tabela 3 - Identificação dos organismos na Seção 1.

\begin{tabular}{ccccc}
\hline Espécie & Tipo & Onde vivem & $\begin{array}{c}\text { Tipo de } \\
\text { alimento }\end{array}$ & $\begin{array}{c}\text { Indicação de } \\
\text { qualidade da água }\end{array}$ \\
\hline Diptera Culicidae & $\begin{array}{c}\text { Insetos, larvas sem } \\
\text { pernas }\end{array}$ & Nadadores & Filtradores & Extremamente poluída
\end{tabular}



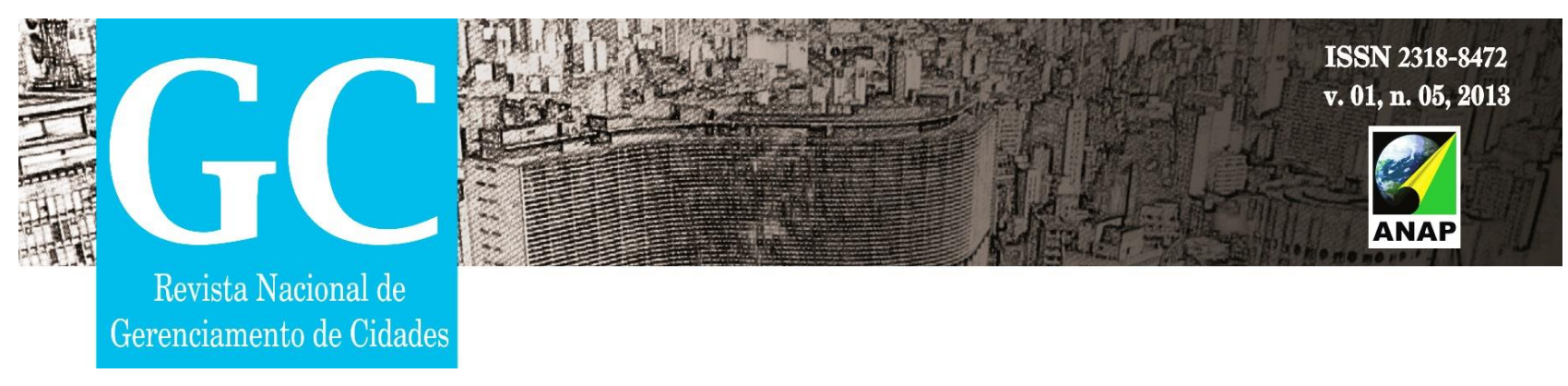

\begin{tabular}{|c|c|c|c|c|}
\hline Coleoptera (larva) & $\begin{array}{l}\text { Insetos, larvas e } \\
\text { adultos com pernas }\end{array}$ & $\begin{array}{l}\text { Pedras e } \\
\text { vegetação }\end{array}$ & Raspadores & Muito poluída \\
\hline $\begin{array}{c}\text { Coleoptera (Besouro } \\
\text { adulto) }\end{array}$ & $\begin{array}{l}\text { Insetos, larvas e } \\
\text { adultos com pernas }\end{array}$ & Nadador & Predador & Muito poluída \\
\hline $\begin{array}{l}\text { Ephemeroptera } \\
\text { Baetidae }\end{array}$ & $\begin{array}{l}\text { Insetos, larvas e } \\
\text { adultos com pernas }\end{array}$ & Pedras & $\begin{array}{l}\text { Coletores e } \\
\text { raspadores }\end{array}$ & Água muito limpa \\
\hline
\end{tabular}

Elaborado por: CARDOSO; NOVAES (2013).

De acordo com Matos (2009), a ordem das dípteras, pertencentes às famílias culicidae e chironomidae (espécie mais encontrada nas amostras), são os organismos que apresentam maior resistência à degradação ambiental. Portanto, se encontrada sozinha, sem outros organismos mais tolerantes, mostrará forte perturbação na qualidade da água no trecho em análise. Além disso, as consequências para a população de seu entorno será preocupante, visto que os mesmos são vetores de doenças.

Tabela 4 - Identificação dos organismos na Seção 2.

\begin{tabular}{|c|c|c|c|c|}
\hline Espécie & Tipo & Onde vivem & $\begin{array}{l}\text { Tipo de } \\
\text { alimento }\end{array}$ & $\begin{array}{c}\text { Indicação de } \\
\text { qualidade da água }\end{array}$ \\
\hline Diptera Simulidae & $\begin{array}{l}\text { Insetos, larvas sem } \\
\text { pernas }\end{array}$ & Pedras & Filtradores & Extremamente poluída \\
\hline Oligochaeta & Não inseto & Sedimentos & Coletores & Extremamente poluída \\
\hline $\begin{array}{c}\text { Diptera } \\
\text { Chiromomidae }\end{array}$ & $\begin{array}{l}\text { Insetos, larvas sem } \\
\text { pernas }\end{array}$ & $\begin{array}{l}\text { Pedras e } \\
\text { sedimentos }\end{array}$ & Coletores & Extremamente poluída \\
\hline Ephemeroptera & $\begin{array}{l}\text { Insetos, larvas e } \\
\text { adultos com pernas }\end{array}$ & Pedras & Raspadores & Água muito limpa \\
\hline $\begin{array}{l}\text { Ephemeroptera } \\
\text { Baetidae }\end{array}$ & $\begin{array}{l}\text { Insetos, larvas e } \\
\text { adultos com pernas }\end{array}$ & Pedras & $\begin{array}{l}\text { Coletores e } \\
\text { raspadores }\end{array}$ & Água muito limpa \\
\hline
\end{tabular}

Elaborado por: CARDOSO; NOVAES (2013). 

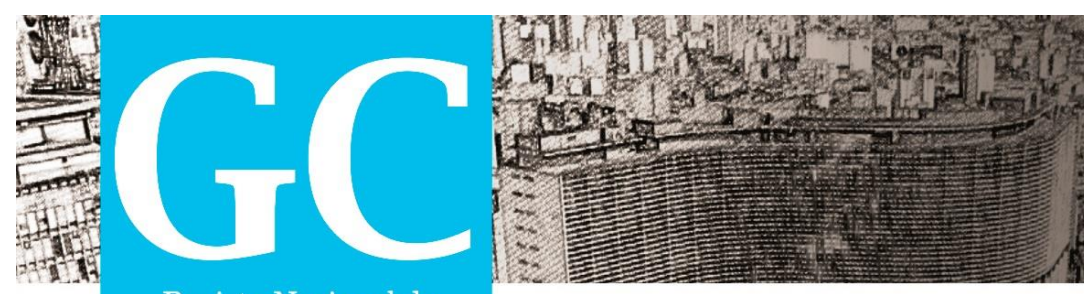

Revista Nacional de

Gerenciamento de Cidades

De modo geral, as seções amostradas apresentam baixa qualidade da água, com base nos organismos identificados no curso d'água (grande número de insetos ou larvas sem pernas - associadas às águas extremamente poluídas; e um ou outro inseto e larva com pernas, normalmente encontrados em águas limpas). O que pode ser resultado de atividades antrópicas tais como a presença de efluentes liberados sem tratamento nos corpos receptores, resíduos sólidos, material orgânico e químico poluentes.

\section{CONSIDERAÇÕES FINAIS}

Em uma bacia com parcelas urbanizadas, mas com grandes interferências antrópicas como a do Cedro, as interações entre sociedade e natureza estão sujeitas à adição dos resíduos oriundos destas atividades ao curso d'água. Desta forma, foi de fundamental importância analisar as variáveis físico-químicas e biológicas para aferir a qualidade da água para os organismos aquáticos e para a população.

De maneira geral, a área dos Conjuntos Habitacionais apresenta vertentes íngremes com cobertura de gramíneas e que recebem grande quantidade de água das galerias pluviais que não foram planejadas de maneira adequada às condições do relevo. O impacto do escoamento superficial dessa água tem agravado os processos erosivos e a ineficiência da manutenção de ravinas e voçorocas contribui ainda mais para o transporte de sedimentos da vertente até o curso d'água.

Além disso, junto com o escoamento são transportados materiais úrbicos (sofás, sacos plásticos, materiais de construções etc.) e gárbicos (lixo orgânico de origem humana) até o curso d'água. Estes, que caracterizam a entrada de matéria orgânica de origem antrópica no meio aquático, resultam no aumento da quantidade de nutrientes disponíveis no meio, desequilibrando os processos de fotossíntese e decomposição.

Outra problemática identificada está relacionada aos indícios de vazamentos na rede de coleta de esgotos domésticos, que alteram significativamente as características físicas, químicas e biológicas da água (processo de eutrofização do rio). Isso foi expresso 


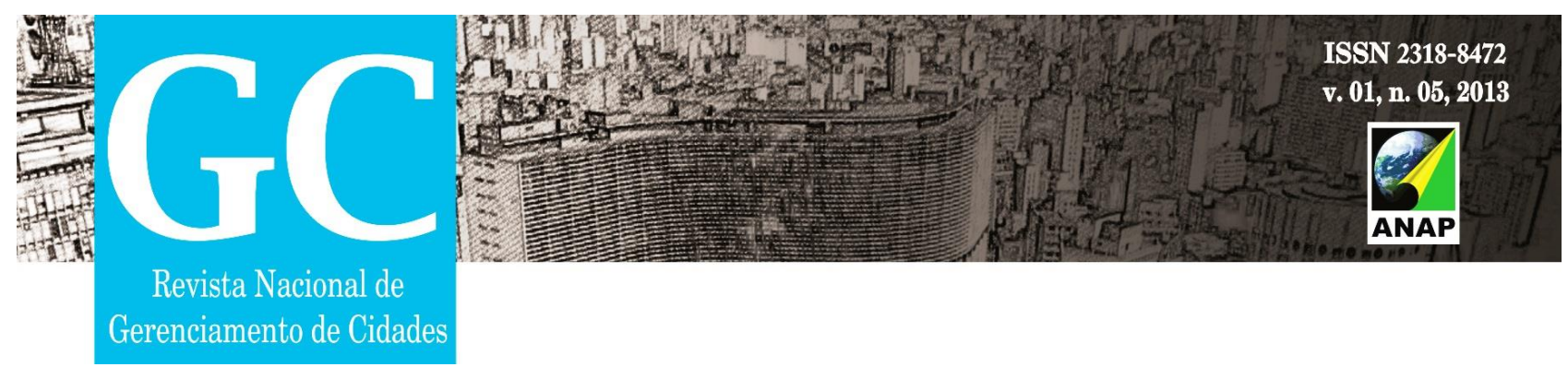

nos dados amostrados, principalmente no que diz respeito aos tipos predominantes de macroinvertebrados bentônicos encontrados, que remetem à péssima qualidade da água.

Nesse contexto, ressalta-se a importância de um monitoramento espacial e temporal dos recursos hídricos, visto que as modificações provocadas pela ação antrópica nos ambientes fluviais têm alterado sobremaneira sua dinâmica, poluindo o meio físico e interferindo negativamente na qualidade de vida no ecossistema lótico e da população.

\section{REFERÊNCIAS}

ARAUJO, A. P. Avaliação Espaço-Temporal de erosão nas margens no córrego do Cedro em Presidente prudente, São Paulo, Brasil - Faculdade de Ciências e Tecnologia, Universidade Estadual Paulista, Presidente Prudente, 2009. Disponível em: <http://egal2009.easyplanners.info/ area07/7028_Araujo_Alex_Paulo.pdf> Acesso em: 21 jun. 2013.

ARROIO JUNIOR, P. P.; ARAÚJO, R. R.; SOUZA, A. Monitoramento da qualidade da água no manancial do rio Santo Anastácio. Colloquium Exactarum, Presidente Prudente, v. 3, n. 1, p. 1017, jan/jun 2011. DOI: 10.5747/ce.2011.v03.n1.e022. Disponível em: < http://revistas.unoeste.br /revistas/ojs/index.php/ce/article/viewFile/569/909>. Acesso em: 22 jun. 2013.

BAPTISTA, D. F.; BUSS, D. F.; DORVILLÉ, L. F. M.; NESSIMIAN, J. L. O conceito de continuidade de rios é válido para rios de mata atlântica no sudeste do Brasil? In: Ecologia de Insetos Aquáticos. Séries Oecologia Brasiliensis, v.5, p.209-222. PPGE-UFRJ. Rio de Janeiro. 1998.

CALLISTO, M.; MORETTI, M.; GOULART, M. Macroinvertebrados bentônicos como ferramenta para avaliar a saúde dos riachos. Revista Brasileira de Recursos Hídricos 1: 71-82, 2001.

CALLISTO, M.; MORENO, P. Biomonitoramento de macroinvertebrados bentônicos: consolidando passos na busca do desenvolvimento sustentável Sociedade Brasileira de Limnologia. Boletim Científico, ํo 35 (2) p. 40 - 42, setembro 2006.

CANGANI, M. T.; POLEGATTO, J. C.; ROCHA, R. R. A. Monitoramento e análise da qualidade da água a partir de variáveis limnológicas. Anais... Encontro de Ensino, Pesquisa e Extensão da Unoeste - ENEPE. Presidente Prudente, 2008. Disponível em: < http://www.unoeste.br/site/pos /enepe/anais/2008/docs/posteres/enapi/expandido/Expandido ExatasGeoci\%C3\%AAncias PosterPesquisa.pdf>. Acesso em: 27 jun. 2013. 


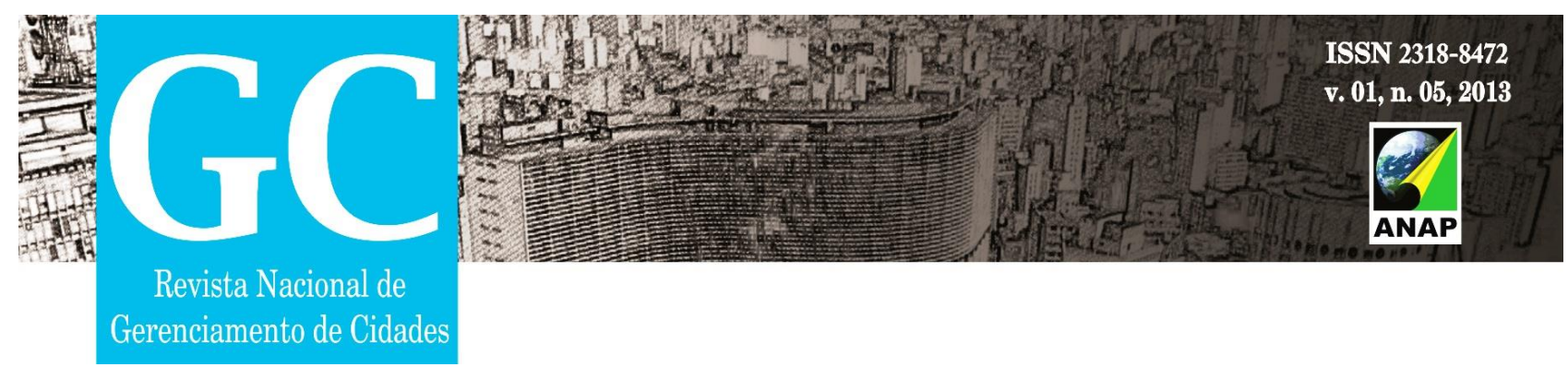

COMPANHIA AMBIENTAL DO ESTADO DE SÃO PAULO - CETESB. Alterações físicoquímicas. Disponível em:<http://www.cetesb.sp.gov.br/mortandade/causas_ph.php>. Acesso em: 21 jun. 2013a.

COMPANHIA AMBIENTAL DO ESTADO DE SÃO PAULO - CETESB. Turbidez. Disponível em:<http://www.cetesb.sp.gov.br/userfiles/file/agua/aguassuperficiais/aguasinteriores/variave is/aguas/variaveis_fisicas/turbidez.pdf $>$. Acesso em: 21 jun. 2013b.

COMPANHIA AMBIENTAL DO ESTADO DE SÃO PAULO - CETESB. Condutividade. Disponível em:< http://www.cetesb.sp.gov.br/userfiles/file/agua/aguas-superficiais/aguas-

interiores/variaveis/aguas/variaveis_quimicas/condutividade.pdf>. Acesso em: 21 jun. 2013c.

CUMMINS, K. W.; MERRITT, R. W. Ecology and distribution of aquatic insects. In: MERRITT, R. W.; CUMMINS, K. W. (Ed.). An introduction to the aquatic insects of North America. Dubuque: Kendall/Hunt, 1996. cap. 6, p. 74-86.

DIBIESO, E. P. Planejamento Ambiental da Bacia Hidrográfica do Córrego do Cedro Presidente Prudente/SP- Faculdade de Ciências e Tecnologia, Universidade Estadual Paulista, Presidente Prudente, 2007. Disponível em: <http://www.athena.biblioteca.unesp.br/exlibris /bd/bpp/33004129042P3/2007/dibieso_ep_me_prud_prot.pdf> Acesso em: 1 de dez. de 2011.

DODDS, W.K.; JONES, J.R.; WELCH, E.B. Suggested classification of stream trophic state: distributions of temperate stream types by chlorophyll, total nitrogen, and phosphorus. Water Resources 32(5): 1455-1462, 1998.

FERRAZ, D. R.; AMARAL, A. A. Variação nictemeral dos parâmetros físico-químicos da água de um viveiro de cultivo de tilápia. Anais... XIV Encontro Latino Americano de Iniciação Científica e X Encontro Latino Americano de Pós-Graduação - Universidade do Vale do Paraíba. São José dos Campos, 2010.

LEOPOLD, L.B.; MADDOCK, T. The hydraulic geometry of stream channels and some physiographic implications. United States Geological Survey, Prof. Paper. 252, 56p, 1953.

MATOS, R. J. Planejamento Ambiental na Bacia do Manancial Rio Santo Anastácio: estudo aplicado a sub-bacia do córrego Botafogo / Presidente Prudente. 2009. Monografia (Bacharel em Geografia) - Universidade Estadual Paulista, Faculdade de Ciências e Tecnologia.

RIBEIRO, F. L.; CAMPOS, S. Vulnerabilidade à erosão do solo da região do Alto Rio Pardo, Pardinho, SP. Rev. bras. eng. agríc. ambient. [online]. 2007, vol.11, n.6, pp. 628-636. ISSN 1807-1929.

SANTOS, R. P.; TERRA, V. R.; AZEVEDO JUNIOR, R. R.; SÁ, F. S.; KIFFER JUNIOR, W. P. Estrutura da comunidade de macroinvertebrados bentônicos associados a macrófitas em um rio lótico neotropical, no sudeste do Brasil. In: Natureza on line: ESFA, v.9, n.2, p. 62-66. 2011.

SILVA, F. L.; PAULETO, G. M.; TALAMONI, J. L. B.; RUIZ, S. S. Categorização funcional trófica das comunidades de macroinvertebrados de dois reservatórios na região Centro-Oeste do Estado 

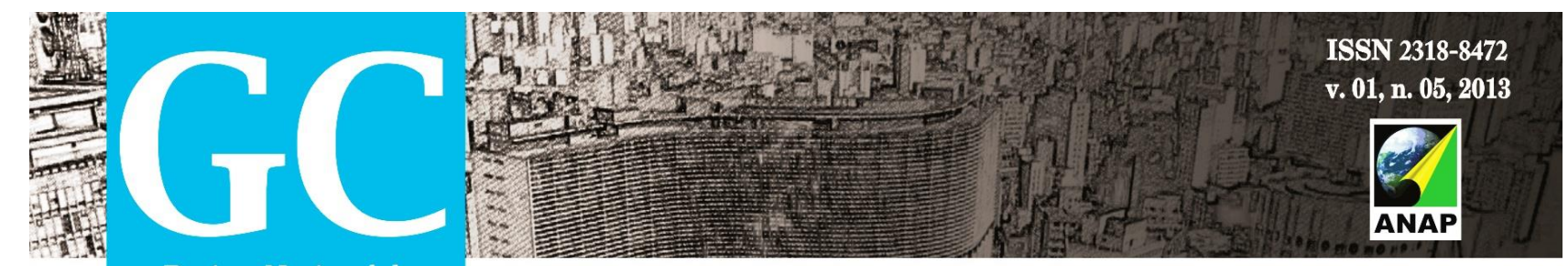

Revista Nacional de

Gerenciamento de Cidades

de São Paulo, Brasil do Estado de São Paulo, Brasil. In: Acta Scientiarum. Biological Sciences. Maringá, v. 31, n. 1, p. 73-78, 2009.

UNIVERSIDADE FEDERAL RURAL DO RIO DE JANEIRO (UFRRJ). Instituto de Tecnologia.

Temperatura da água. Disponível em: < http://www.ufrrj.br/institutos/it/de/ acidentes/tem. htm>. Acesso em: 11 jul. 2013.

VANNOTE, R.L., MINSHALL, G.W., CUMMINS, K.W., SEDELL, J.R. \& CUSHING, C.E. The river continuum concept. Can. J. Fish. Aquat. Sci.vol.37. p. 130-137, 1980. 